to early childhood, but others receive a bump start later in life from a mentor or teacher, and many illustrate how chance encounters provoke a dramatic new direction. Without providing any general conclusions, these essays offer the idiosyncrasy and curiosity value that we expect of good, narrative history, combined with much fine writing.

Two contributors - Stephen Pinker and Judith Harris - adopt a scientistic stance toward the whole narrative enterprise. Don't trust our childhood recollections, they caution, and certainly beware of any causal connections that we infer. Psychological research on the unreliability of childhood memories and our frequent lack of introspective access to potent influences on our choices lend weight to their cautionary remarks. But few readers will feel comfortable reading these accounts so sceptically. Many of the contributors revisit their childhood with gusto - and with palpable curiosity. What they write is quirky, absorbing and persuasive in just the way that good stories are.

Paul L. Harris is at the Harvard Graduate School of Education, 503A Larsen Hall, Appian Way, Cambridge, Massachusetts 02138, USA.

\section{Stalking life's second secret}

The Proteus Effect: Stem Cells and their Promise for Medicine by Ann B. Parson

Joseph Henry Press: 2004. 304 pp. \$24.95

\section{Lee M. Silver}

On 28 February 1953, Francis Crick famously burst into a Cambridge pub with Jim Watson in tow and exclaimed triumphantly: "We have found the secret of life!" The rest, as the cliché goes, is history. Both scholarly and popular accounts of the personalities and events surrounding the discovery of the double helix, and subsequent advances in molecular genetics, have appeared in tens of thousands of books and articles. The DNA story is taught in school biology classes to eight-year-old children. Several DNA-based Nobel prizes have already been won, and more are no doubt waiting in the wings.

Genes and genomes, however, represent only one of two pillars of likely twenty-firstcentury progress in biomedicine. The second is stem-cell biology. And yet, while everyone knows of Watson and Crick, hardly anyone has heard of Leroy Stevens and other early stem-cell pioneers. Indeed, many scientists are unaware of the five decades of advances that occurred before the 1998 isolation of human embryonic stem cells. In her new book The Proteus Effect, journalist Ann
Parson fills the gap with a breezy, easily accessible narrative of the people, results and ideas that have shaped the field.

Parson traces the birth of modern stem-cell research back to 1953, the same year that the double helix made its debut. Although the means for composing and reproducing life's genetic recipes had been a fundamental secret of life, it was not the only one. A second mystery was the process by which a microscopic embryo could develop into a fully functional human being or other mammal. Embryologists knew that development occurred through the controlled growth, division and specialization of individual cells, but they didn't know how developmental control was asserted. Many assumed, without evidence, that a permanent loss of biological components or capabilities was responsible for the narrowing of cellular potential. By implication, it seemed that a postembryonic mammalian cell should never be able to reverse course and return to an embryonic state. The exceptions were the germ cells (eggs and sperm), which still had the potential to retrace normal development only after combining with each other.

Goal-oriented unidirectional development was easily accepted as scientific dogma because it aligns neatly with traditional Judaeo-Christian-derived religious doctrine, which permeates Western culture. As recently as 2002, Princeton professor Robert George - a defender of strict Catholicism and member of President Bush's Council on Bioethics - claimed the mantle of science when he wrote that the direction of a human embryo's growth "is not extrinsically determined, but is in accord with the genetic information within it ... It is clear that from the zygote stage forward, the major development of this organism is controlled and directed from within, that is, by the organism itself" (George's emphases). Consequently, according to George and others on the council and in the Bush administration, human zygotes and blastocysts (newly fertilized embryos that have just started to divide) are "already living human beings" deserving of protection from the murderous pursuits of biomedical scientists. Perhaps George would come to realize how outdated his views of embryology are if he read Ann Parson's book (and then again, perhaps not).

In the winter of 1953, Leroy Stevens was searching for morphological differences among inbred mice at the Jackson Laboratory in Bar Harbor, Maine, when he chanced upon the observation of an enlarged testicle in about $1 \%$ of adult males of the 129 strain. The cause of the enlargements was an inde-

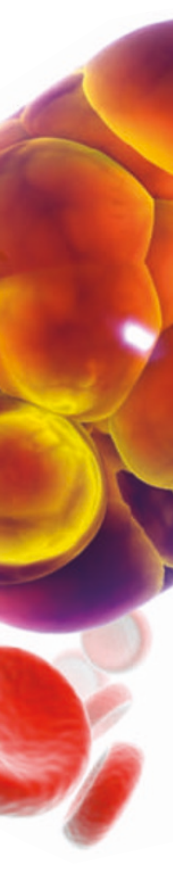

pendently growing mass of a type previously found only in human patients. It was called a teratoma because of its monster-like characteristics. Human teratomas are typically covered with skin and hair, and contain a bizarre diversity of tissues and organs normally found in other parts of the adult body, including synaptically connected neurons, muscle, beating heart tissue, bone, teeth and sometimes eye-like entities or whole limbs. Stevens realized that the 129 strain's predisposition to develop teratomas gave him a unique tool for tackling the mystery of their origin, which could provide insight into normal developmental processes.

Two years and 17,000 animals later, Stevens had dissected his way back through younger and younger mice, and ultimately fetuses, to discover that random genitalridge cells occasionally flew off-course and developed like the innards of early embryos before exploding into teratomas. In other strains, females were predisposed to teratoma formation. Ovarian cells morphed, by themselves, into an organism that Stevens said "looked just like a normal embryo, but then it would all get mixed up. It became disorganized and you had a tumour instead of a baby mouse." Stevens didn't think that mutant genes were the main trigger of this aberrant development, and when he placed normally fertilized embryos into unusual environments, such as the kidney capsule, they also became teratomas instead of mice.

Teratomas are not ordinary tumours. Along with their adult tissues, some contain cells that can grow and divide for years without becoming specialized. When dispersed and injected into mouse abdomens, these cells developed into "thousands of small structures resembling 5- or 6-day mouse embryos floating freely". Stevens was convinced that such "embryonic carcinoma" 
cells had the capacity to settle down and participate in completely normal tissue and organ development if given a chance in a normal embryonic environment. The embryologists Ralph Brinster, Beatrice Mintz and Richard Gardner proved him right by producing chimaeric mice derived from a mixture of normal embryo cells and embryonic carcinoma cells.

If this were the whole story, teratomas would have remained no more than interesting medical oddities. But, in 1981, Martin Evans and Matthew Kaufman of Cambridge University, and Gail Martin at the University of California, San Francisco, independently

\section{Food for thought for geneticists}

\section{Why Some Like It Hot: Food, Genes and Cultural Diversity \\ by Gary Paul Nabhan \\ Island Press: 2004.223 pp. \$24}

\section{T. Colin Campbell}

It's not that we are what we eat, proposes Gary Nabhan, but rather, we are what foods our ancestors ate and what genes they gave to us. In Why Some Like it Hot, Nabhan argues that natural selection and other evolutionary processes mediated by food choices unique to each geoclimatic and cultural domain have played important roles in generating human genetic diversity.

According to Nabhan, the time period for this evolution is likely to have been much shorter than is generally supposed. Our unique gene profiles evolved within the past few thousand years or so, perhaps as mutations caused by secondary compounds in staple foods and culinary herbs that were indigenous to certain geoclimatic regions. These genomic profiles could have been moulded by food choices, and by pressure from endemic diseases, to reduce the risk of disease.

This view departs from the darwinian idea that our current gene pool resulted from a very slow process of random selection to maximize individuals' survival. The fact that $99.9 \%$ of our genome is shared by all humans, present and past, is cited as evidence of an exceptional genetic stability that arose many millennia ago, perhaps during and before Palaeolithic times.

This observation of early genetic similarity and stability has suggested to some observers that there is a one-size-fits-all diet, perhaps one that was commonly used during Palaeolithic times, but Nabhan challenges this view. He points out, as others have, that of the 3 billion nucleotides in the human genome, 3 million of them $(0.1 \%)$ have remained in play and can be used to create genetic diversity. A change of only one grabbed the reins of development when they extracted embryonic stem cells directly from mouse embryos and kept them growing in culture indefinitely without differentiating. In 1998, the same process was perfected for use with human embryos, and the age of regenerative medicine was initiated. The goal now is to discover the factors and conditions that will transform embryonic-like cells into whatever tissue is required to overcome a particular disease or human condition.

Parson engages the debate between supporters and opponents of human embryo research by allowing the main players to speak for themselves. She doesn't advocate

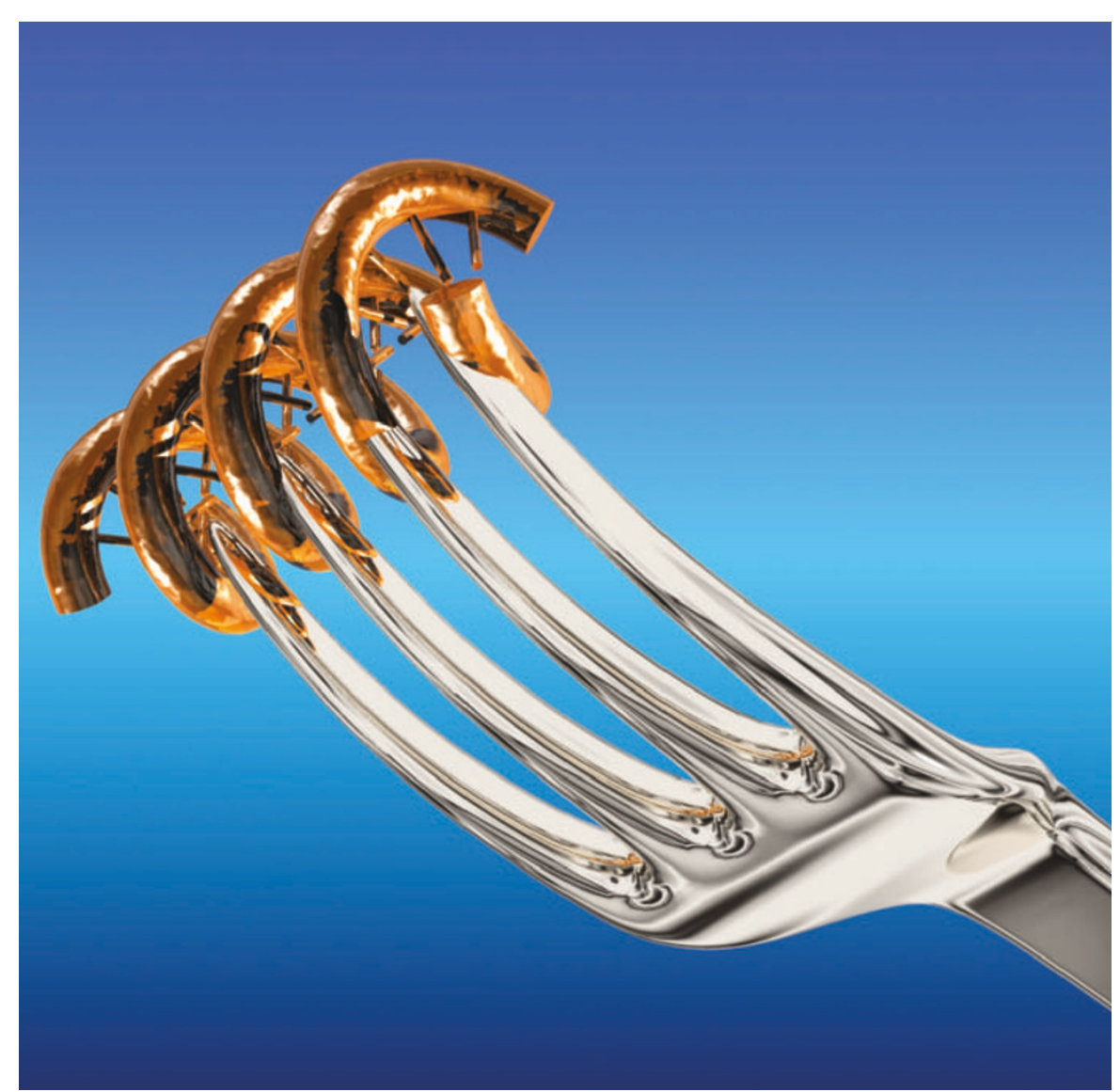

nucleotide can make a substantial difference.

Nabhan identifies a group of 26 'disease genes' that are likely to have been fashioned by food factors and endemic diseases. $\mathrm{He}$ cites adult-onset diabetes, lactose intolerance and heritable food allergies as examples of interactions between genes, food and disease. He goes on to say that a large number of us are subject to one or more of these genetic 'disorders', as some would call them indeed they are so common that they should be considered normal.

He discusses in considerable depth the extensively studied link between malaria, sickle-cell anaemia, the consumption of fava beans, and glucose 6-phosphate dehydrogenase (G6PD) deficiency, in order to illustrate how a careful study of biology, culture and history can be much more rewarding than for or against, although the book's subtitle leaves no doubt as to her own position. The final chapter provides a balanced assessment of the therapeutic potential of stem cells in both the short and the long term, disease by disease and organ by organ. All in all, Parson admirably brings to life the stem-cell story from a tiny Maine fishing village to the battle for the American presidency in 2004.

Lee M. Silver is a professor of molecular biology and public affairs at Princeton University,

Princeton, New Jersey 08544, USA. He is the author of the forthcoming book Biotechnology in a Spiritual World (Ecco Press). one of these disciplines alone. He takes the reader on a trail of discovery, visiting the Mediterranean island of Sardinia, where malaria has long been endemic. Here the traditional springtime consumption of fava beans offers those with the genetic disorder of G6PD deficiency some protection against the mosquito-borne disease. Coupling cultural, biological and historical analyses in this way is the basis for the field of nutritional ecogenetics.

Nabhan also cites examples that tend to be found in regions of the world, particularly islands, where the resulting interactions became reasonably well established and remained stable. For example, on the island of Crete and elsewhere in the Mediterranean region, a high-fat diet is associated with a lower risk of heart disease than would be 